\title{
Laser Doppler Flow Meter: A New Approach for Calculation of Human Blood Flow Rate
}

\author{
Nikhil A. Shinde \\ Student ME VLSI \& Embedded \\ System,Shree Ramchandra \\ college of engineering \\ Lonikand (Pune), India
}

\author{
K. Sujatha \\ HOD Of E\&TC Department \\ Shri Ramchandra College Of \\ Engineering Lonikand Pune
}

\author{
Ashlesha Kulkarni \\ Lecturer at E\&TC Department \\ SIT Polytechnic Yadrav, \\ Ichalkaranji
}

\begin{abstract}
In this paper, we are going to introduce the new technique for measurement of blood flow rate in humans based on LDF (Laser Doppler Flowmetry) technique. We had developed overall embedded system which takes input from laser Doppler blood flow sensor \& gives output on personal computer via wireless communication. The structure of the sensor consists of two compartments with a light dependant resistor (LDR) and a laser diode in each. The size \& weight of sensor \& overall system is very less. The overall system is powered through a dedicated battery \& hence power saving arrangement is also provided. Proper blood flow in human body is essential because an adequate amount of blood supply is necessary for the proper functioning of all body organs as blood carries all the nutrients and oxygen that our body needs to stay healthy. Improper blood flow rate is main symptoms of various diseases. The measurement of the blood flow can therefore provide essential information for the judgment of diseases. Since changes in blood flow occurs with the very primary stage of disease, with a fast, reliable blood flow measurement technique, the physicians have a new option for early disease diagnosis. So using this system, we can successfully $\&$ easily able to measure human blood flow rate. Major advantage of this technique is this method is noninvasive which means not involving the introduction of instruments into the body[1][2]
\end{abstract}

\section{Keywords}

blood flow, laser Doppler flowmetry, low power consumption, LDF Sensor, wireless, non-invasive

\section{INTRODUCTION}

Now days, biomedical engineering is fast emerging field. Biomedical engineers analyze and design solutions to problems in biology and medicine, with the goal of improving the quality and effectiveness of patient care. Every day various biomedical instruments are used to measure human health information such as blood pressure, heart rate, and electrocardiogram (ECG) to detect health problems. This in formation is also used for defining health status of patient $\&$ diagnosis of various diseases. Provoked by these broad and important applications, we developed embedded system used for human blood flow rate measurement using laser Doppler Flowmetry (LDF) as a noninvasive method of measuring blood flow. Mainly this method is noninvasive which means we don't have to introduce any instrument into the body, means we can externally take the reading without any difficulty. The sensor size is very small and also consumes little power, making it suitable to be mounted on a human. In studying blood flow data, we found strong indication that blood flow is depend upon biomedical signals in humans, such as sympathetic and parasympathetic-related feelings, emotions, and drowsiness. The same is true for animal blood flow.

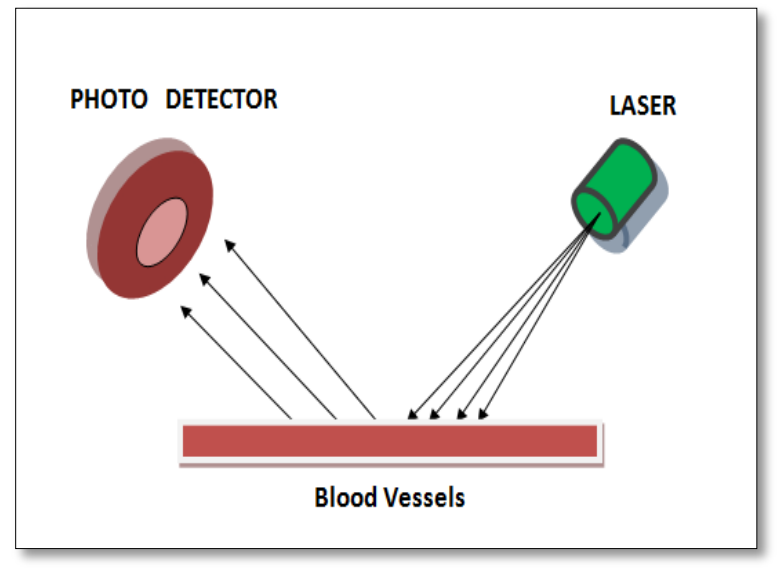

Fig 1: Blood flow measurement using LDF

In the current paper, we are going to describe a laser Doppler blood flow micrometer, which we have developed for use with humans. This device is wireless, weighs very less, and has low power consumption. We can easily found blood flow rate of human with this sensor. Even this type of system is useful in medical field.[1][7]

\section{WHAT IS BLOOD FLOW?}

Blood flow rate is depending upon two factors:

\section{Pressure exerted by heart}

\section{Resistance of blood vessels}

If pressure exerted by heart is higher, then blood flow rate is also higher. This indicates that blood flow rate is directly proportional to pressure exerted by heart.

There is one another factor which is used to measure the blood flow rate, and this factor is resistance of the blood vessels to blood flow. This resistance is occurring due to the width of the vessels Thus blood vessel resistance is inversely proportional to the blood flow rate - the higher the resistance, the lower the flow rate.

The relationship is as follows:

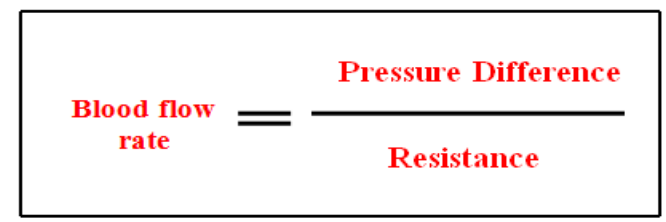




\subsection{Relation between Heart rate \& Blood flow:}

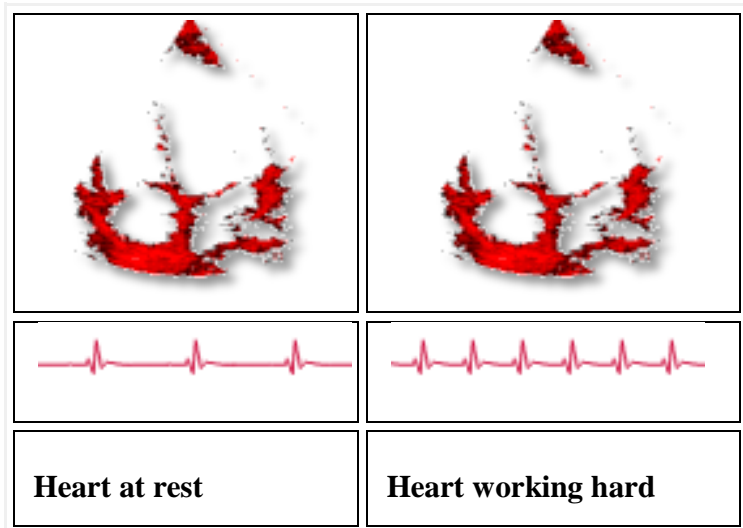

Fig 2: Heart rate \& Blood flow

Lot of energy is used in exercise, which the cells derive from oxidizing glucose. Both glucose and oxygen have to be prepared by the blood. This means blood flow rate is multiplication of heart rate and blood stroke volume. This is given by the formula:

Blood flow rate $=$ Heart Rate $\mathrm{x}$ Stroke Volume

\subsection{Heart rate in different mammals:}

Although all mammals have circulatory systems similar to humans, heart rates among species are not at all similar. In general, larger the animal, slower its resting heart rate. Camels and bats represent the two extremes of the scale, with most other mammals falling somewhere in between.[4]

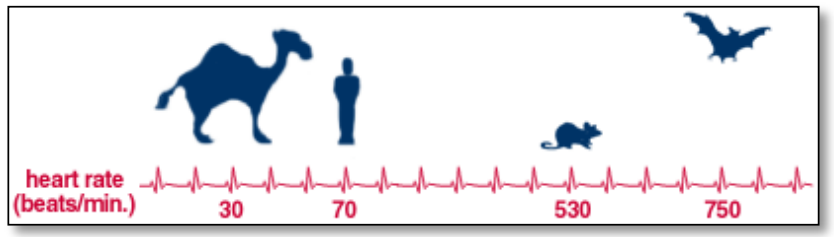

Fig 3: Heart rate in different mammals

\section{METHODS FOR BLOOD FLOW MEASUREMENTS}

The methods of blood flow measurement are divided into following two main types

1. Invasive methods

2. Non Invasive methods

Non Invasive methods are further classified in to following subtypes

- Ultrasound Doppler

- Laser Doppler Flowmetry

- Strain Gage Plethysmography

- Electric-Impedance Plethysmography

- Photoelectric Plethysmography

- Thermal Convection Probes

Similarly Invasive methods are further classified in to following subtypes

- Dye Dilution Method

- Thermal Dilution Method

- Radioisotopes
Out of this all methods we are going to focus on Laser Doppler Flowmetry(LDF).First we see fundamental concept of Laser Doppler Flowmetry.

Laser Doppler Flowmetry (LDF) is a non-invasive method to estimate the blood flow rate. The method was first introduced over 30 years ago and has undergone a continuous development since Laser Doppler Flowmetry (LDF) is an accurate and reliable method for assessing blood flow rate.[5]

\section{WORKING OF LASER DOPPLER FLOWMETRY}

Fig 4 shows how actual LDF works. In LDF technique, tissue is illuminated by low power laser light. The light is scattered by the static tissue structures and moving blood cells. Some portion of the laser light is Doppler shifted. The Doppler shifted light is converted into electrical signal by LDR (Light dependant resistor) \& that electrical signal is proportional to human blood flow rate. That analog electrical signal is converted into digital by DAC \& transferred to receiver by xigbee.[1]

\subsection{Advantages of LDF technique}

The LDF technique offers significant advantages over other methods, in allowing the continuous measurement of micro vascular blood perfusion. The LDF may be used noninvasively (since the sensor is not actually required to touch the surface of the body) and in no way harms or disturbs the normal physiological state of the microcirculation. LDF is both highly sensitive and responsive to local blood perfusion and is also versatile and easy to use for continuous monitoring

- receptive to small changes

- Continuous/real-time - response

- May be used non-invasively, On skin or organ surface where exposed

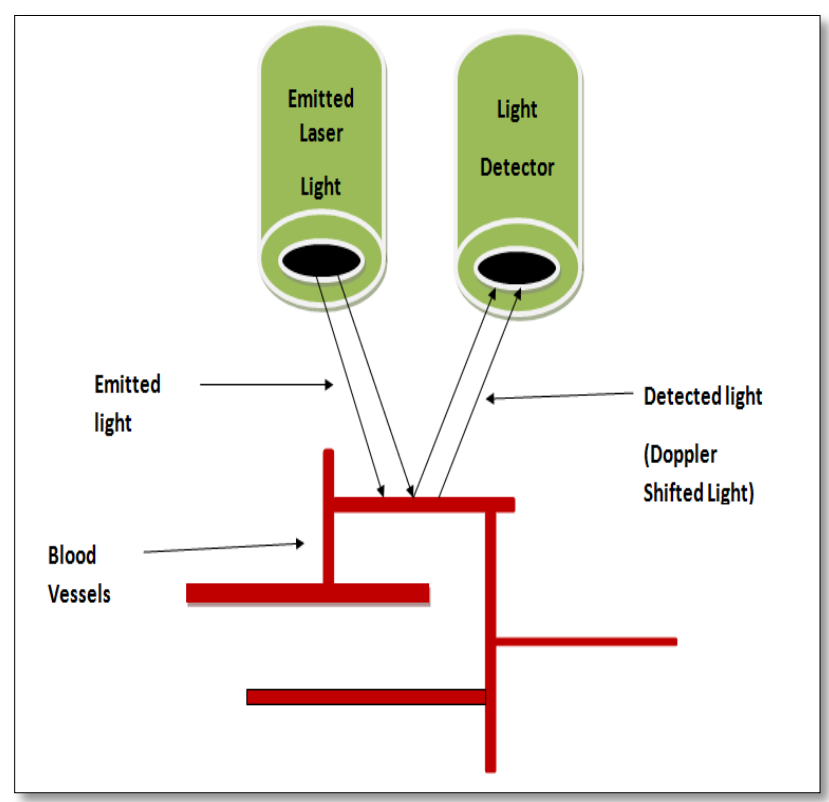

Fig 4: Working of LDF Technique 


\section{DESIGN OF HUMAN BLOOD FLOW METER}

The Design of Human Blood flow meter is as shown in Figure $5.1 \& 5.2$. The overall design is divided into two parts:

\section{Transmitting Section}

2. Receiving Section

Transmitting Section consist of PIC $18 \mathrm{~F} 4550$ microcontroller,Blood Flow sensor,power supply circuit, LCD display \& xigbee transmitter. The blood flow sensor consist of two cavities. Laser diode is placed in one cavity \& Photo detector like LDR is placed in another cavity. The tissue is illuminated by Laser light \& the frequency of laser light is changes according to blood flow rate. The reflected laser light is converted in to electric current by LDR \& that electric current is praportional to blood flow rate. PIC18F 4550 have internal ADC hence analog electrical signal is converted into digital signal that signal is transmitted via xigbee transmitter $\&$ also we get direct value on LCD display as a output

Receiving section consist of xigbee receiver which is connected to personal computer via universal serial bus. We can directly get values of blood flow rate via xigbee receiver. We can continuously get updated value \& compare it on PC. Hence with the help of receiving section, doctors can get blood flow rate values on their personal PC.[1]

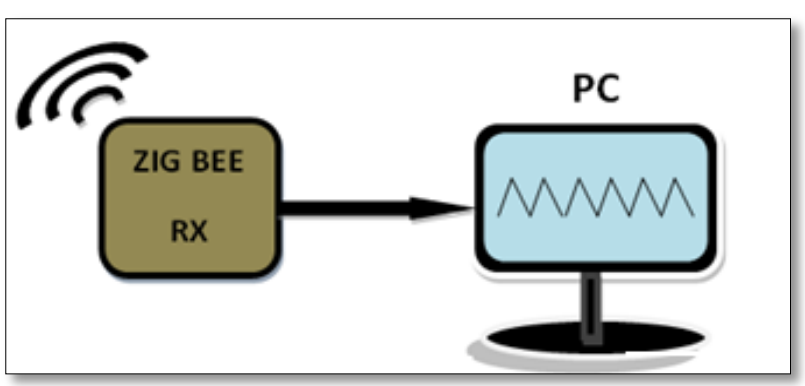

Fig 5 (A): Receiving Section of Human Blood Flow Meter

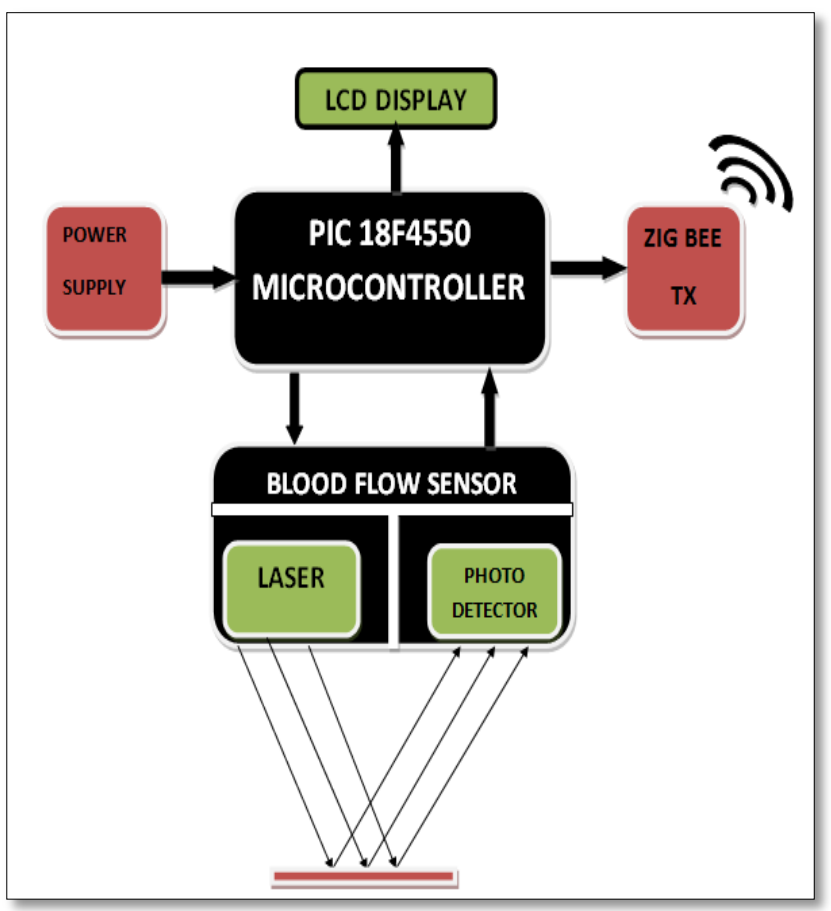

Fig 5 (B): Transmitting Section of Human Blood Flow Meter

\section{RESULTS}

Table showing some observations of blood flow measurement taken by human blood flow meter

\begin{tabular}{|l|l|l|}
\hline $\begin{array}{l}\text { Type of } \\
\text { blood } \\
\text { vessels }\end{array}$ & $\begin{array}{l}\text { Theoretical values } \\
\text { of blood flow }\end{array}$ & $\begin{array}{l}\text { Practical values } \\
\text { measured using system }\end{array}$ \\
\hline Aorta & $40-60 \mathrm{Cm} / \mathrm{s}$ & Around $50 \mathrm{Cm} / \mathrm{s}$ \\
\hline Artery & $30-50 \mathrm{Cm} / \mathrm{s}$ & Around $40 \mathrm{Cm} / \mathrm{s}$ \\
\hline Veins & $30-50 \mathrm{Cm} / \mathrm{s}$ & Around $40 \mathrm{Cm} / \mathrm{s}$ \\
\hline Arteriole & $20-40 \mathrm{Cm} / \mathrm{s}$ & Around $30 \mathrm{Cm} / \mathrm{s}$ \\
\hline
\end{tabular}

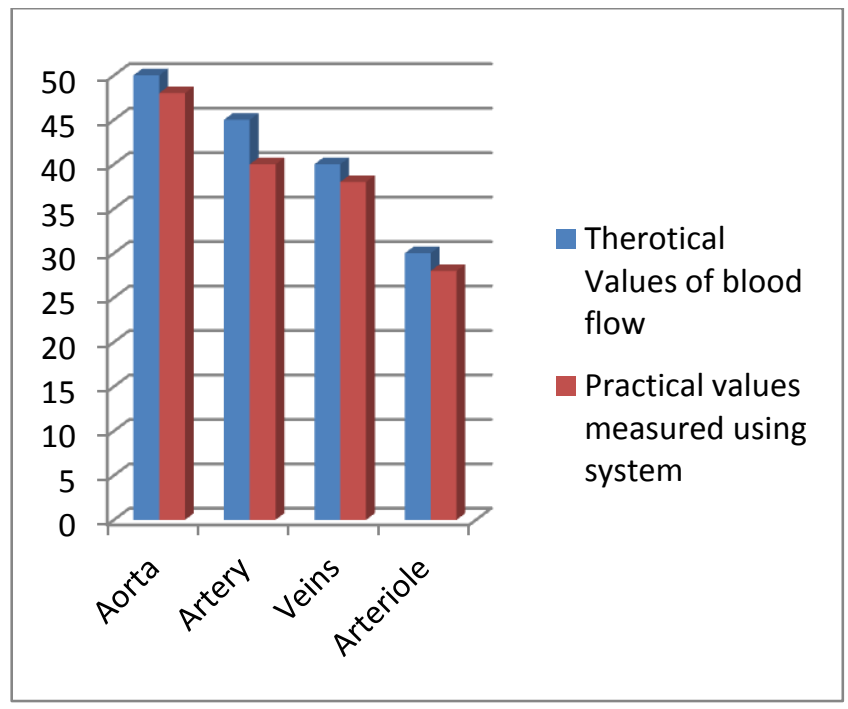

Fig 6: Bar chart showing blood flow rate in different vessels

\section{PHOTOGRAPHS OF LDF BLOOD FLOW METER}

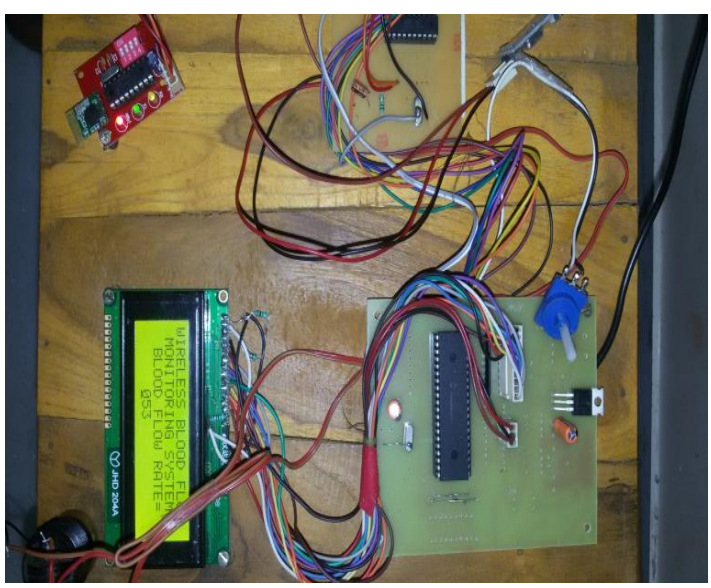

Fig 7: General setup for LDF blood flow meter 


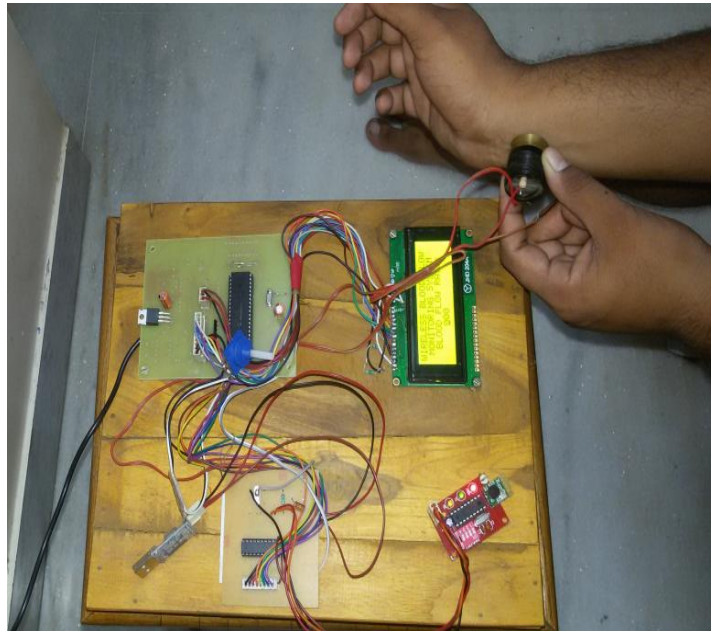

Fig 8: Practical setup for LDF blood flow meter

\section{CONCLUSION}

In this way, we can develop human blood meter to monitor blood flow rate in humans. The LDF sensor weighs is very low and is wearable and wireless. These features enabled us to mount the sensor on humans and monitor their blood flow under daily working conditions. The sensor system is designed to provide stable and reliable blood flow data. Introduction of an discontinuous measuring system made it possible for us to achieve low power consumption, enabling long-term measurement of blood flow. This complete system can work on dedicated batteries.

\section{REFERENCES}

[1] Kei Nishihara, Wataru Iwasaki, Masaki Nakamura, Eiji Higurashi, Member, IEEE, Tomoki Soh, Toshihiro Itoh, Hironao Okada, Ryutaro Maeda, and Renshi Sawada "Development of a Wireless Sensor for the Measurement of Chicken Blood Flow Using the Laser Doppler Blood Flow Meter Technique" in IEEE TRANSACTIONS ON BIOMEDICAL ENGINEERING, VOL. 60, NO. 6, JUNE 2013
[2] G. Lopez, M. Shuzo, and I. Yamada, "New healthcare society supported by wearable sensors and information mappling based services," Int. J. Netw. Virtual Org., vol. 9, pp. 233-247, 2011

[3] Y. Kimura, A. Onoe, E. Higurashi, and R. Sawada, "Low-power consumption integrated laser Doppler blood flowmeter with a built-in silicon microlens," in Proc. Int. Conf. Opt. MEMS Nanophoton., Freiburg, Germany, Aug. 2010, pp. 13-14.

[4] Y. Kimura, M. Goma, A. Onoe, E. Higurashi, and R. Sawada, "Integrated laser Doppler blood flowmeter designed to enable wafar-level packaging," IEEE Trans. Biomed. Eng., vol. 57, no. 8, pp. 2026-2033, 2008

[5] K. Itao, "Wearable sensor network connecting artifacts, nature and human being," in Proc. IEEE Sensors Conf.,Atlanta, USA, 2007, pp. 1120-1123.

[6] A. Lymberis, "Advanced wearable health systems and applications - Research and development efforts in the European union,” IEEE Eng. Med. Biol. Mag., vol. 26, no. 3, pp. 29-33, May/Jun. 2007.

[7] R. Bonner and R. Nossal, "Model for laser Doppler measurements of blood flow in tissue," Appl. Opt., vol. 20, pp. 2097-2107, 1981.

[8] Doi, A. Iwasawa, T. Nakamura, and Y. Tanabe, "Plasma melatoninrhythm of the human," Anim. Sci. Technol., vol. 66, pp. 16-26, May 2006

[9] A. N. Serov, J.Nieland, S. Oosterbaan, F. F.M. deMul,H. van Kranenburg H. H. P. Th. Bekman, and W. Steenbergen, "Integrated optoelectronic probe including a vertical cavity surface emitting laser for laser Doppler perfusion monitorin," IEEE Trans. Biomed. Eng., vol. 53, no. 10, pp. 2067-2074, Oct. 2006.

[10] E.Higurashi,R. Sawada, and T. Ito, "An integrated laser blood flowmeter,’J. Lightw. Technol., vol. 21, pp. 591595, 2003. 